\title{
Oridonin Induces a Caspase-Independent But Mitochondria- and MAPK- Dependent Cell Death in the Murine Fibrosarcoma Cell Line L929
}

\author{
Chun-Ling Zhang, ${ }^{a, b}$ Li-Jun Wu, ${ }^{b}$ Shin-ichi Tashiro, ${ }^{c}$ Satoshi Onodera, ${ }^{c}$ and Takashi IkeJima ${ }^{*, b}$ \\ ${ }^{a}$ China-Japan Research Institute of Medical and Pharmaceutical Sciences, Shenyang Pharmaceutical University; \\ Shenyang 110016, China: ${ }^{b}$ Department of Phytochemistry, Shenyang Pharmaceutical University; Shenyang, 110016, \\ China: and ${ }^{c}$ Department of Clinical and Biomedical Sciences, Showa Pharmaceutical University; Tokyo 194-8543, Japan. \\ Received March 3, 2004; accepted June 9, 2004
}

\begin{abstract}
Oridonin, an active component isolated from Rabdosia rubescences, has been reported to exhibit antitumor effects, but little is known about its molecular mechanisms of action. In this study, the growth-inhibitory activity of oridonin for L929 cells is in time- and dose-dependent manner. After treatment with various concentrations of oridonin for $12 \mathrm{~h}$, the majority of L929 cells underwent apoptosis as measured by an LDH activity-based assay. Although apoptotic bodies were observed in oridonin-treated L929 cells, DNA fragmentation as a hallmark of apoptosis was not found. The pan-caspase inhibitor, z-VAD, and caspase-3 inhibitor, z-DEVD, sensitized L929 cells to oridonin, however, a PARP inhibitor (DPQ) effectively blocked oridonin-induced cell death. After 12 h treatment, PARP proenzyme was significantly cleaved. This result indicated that oridonin-induced L929 cell death required PARP degradation in a caspase-independent manner. In addition, an MEK/ERK inhibitor (PD98059) markedly blocked oridonin-induced cell death, whereas a p38 inhibitor (SB203580) and JNK inhibitor (SP600125) weakly protected the cells against death. Treatment with $41.2 \mu_{\mathrm{M}}$ oridonin for $12 \mathrm{~h}$ induced significant and persistent ERK activation and p38 inactivation in L929 cells without evident changes in the protein levels. The responsiveness of ERK and p38 to oridonin suggests the involvement of these kinases in this apoptotic process. Moreover, oridonin increased the ratio of Bax/Bcl-2 protein expression, whereas it had no effect on the expression of Bcl-xL. These results indicate that regulation of the Bcl-2 and MAPK families maybe the effector mechanisms of oridonin-induced L929 cell death, independent of the caspase pathway.
\end{abstract}

Key words oridonin; L929 cell; Bax/Bcl-2; ERK; p38

Oridonin, a diterpenoid isolated from Rabdosia rubescens, has various pharmacological and physiological effects such as anti-inflammation, anti-bacteria, anti-tumor effects ${ }^{1-3)}$ and has been used for the treatment of human cancers, especially esophageal carcinoma. ${ }^{4}$ Our previous study showed that oridonin had cytotoxic effects on four tumor cell types, human melanoma A375-S2, human cervical carcinoma HeLa, human breast adenocarcinoma MCF-7, and murine fibrosarcoma L929. ${ }^{5)}$ However, the mechnasim of this antitumor effect remains unclear.

Caspases are a family of cysteine proteases, which play key roles in promoting the degradative changes associated with apoptosis and are divided into two classes based on the lengths of their $\mathrm{N}$-terminal prodomains, including up-stream caspases such as caspase- 8 and -10 and downstream caspases such as caspase-3, 6 and 7. In general, caspase activation is believed to be involved in apoptosis. $\left.{ }^{6}\right)$ However, some workers have reported that caspases are required for the protection against tumor necrosis factor- $\alpha(\mathrm{TNF} \alpha)$ or CD95-induced L929 cell death, ${ }^{7,8}$ suggesting that the effects of caspases on cell death are not limited to the initiation of apoptosis.

The Bcl-2 family proteins constitute an important control mechanism in the regulation of apoptosis. Some including $\mathrm{Bcl}-2$ and $\mathrm{Bcl}-\mathrm{X}_{\mathrm{L}}$ suppress apoptosis, and others such as Bax and Bid promote apoptosis, and the balance between these two groups determines the fate of cells in many apoptotic systems. ${ }^{9)}$ In many cell types, the distinct MAPK members have been identified. In these extracellular signalregulated kinases (ERKs), stress-activated protein kinases (SAPKs)/c-Jun NH2-terminal kinases (JNKs), and p38 kinase play important signaling roles in the control of cell proliferation and differentiation. Recent studies suggest that
MAPK also regulate the cell cycle, apoptosis, and necrosis. $^{10-12)}$

The aims of this study were to investigate the effector mechanism(s) of oridonin-induced L929 cell death. We demonstrated that oridonin induced L929 cell death through distinct mechanisms and pathways including apoptosis and necrosis, the mechanism of which is in part due to regulation of Bcl-2 family proteins. Moreover, caspases protected L929 cells against death induced by oridonin. Importantly, modulation of MAPK family members had been first evaluated in oridonin-induced L929 cells death, indicating that oridonininduced cell death is closely correlated with the activation of ERK and inactivation of the p38 signaling pathway.

\section{MATERIALS AND METHODS}

Materials Oridonin was isolated from the aerial parts of Rabdosia rubescens. The $95 \%$ ethanol extract of the rabdosia aerial parts was partitioned between water and petroleum ether. The water layer was separated repeatedly by column chromatography on silica gel, and oridonin was then extracted. The structures of the diterpenoids were assigned by comparing the chemical and spectral data $\left({ }^{1} \mathrm{H}-\mathrm{NMR}\right)$ with those reported in the literature. ${ }^{13)}$ The purity of each compound was tested using an HPLC equipped with ultraviolet detector and a Quest 100 RP-18C column $(4 \mathrm{~mm}$ i.d $\times$ $200 \mathrm{~mm}$ ). Oridonin was dissolved in dimethylsulphoxide (DMSO) to make stock solutions, and then diluted in cell culture medium at different concentrations and used immediately. In all assays, the final concentrations of DMSO in the culture medium were below $0.05 \%$.

Pan-caspase inhibitor (z-VAD-fmk), caspase-3 inhibitor 
(z-DEVD-fmk), and caspase- 8 inhibitor (z-IETD-fmk) were purchased from Enzyme Systems (CA, U.S.A.). Caspase-1 inhibitor (Ac-YVAD-cmk) was obtained from Bachem (Bubendorf, Switzerland). Poly (ADP-ribose) polymerase (PARP) inhibitor (DPQ), MEK/ERK inhibitor (PD98059), p38 inhibitor (SB203580), and JNK inhibitor (SP600125) were obtained from Calbiochem (CA, U.S.A.). Polyclonal antibodies against p38, phospho-p38, ERK2, phospho-ERK, JNK, phospho-JNK, PARP, $\beta$-actin, and horseradish peroxidase-conjugated secondary antibodies (goat-anti-rabbit and goat-anti-mouse) were purchased from Santa Cruz Biotechnology (Santa Cruz, CA, U.S.A.). Anti-Bcl-2, Bcl-xL, and Bax were obtained from Oncogene Research Products (Boston, MA, U.S.A.).

Cell Culture The murine fibrosarcoma cells (L929 \#CRL-2148) were purchased from American Type Culture Collection (ATCC, Manassas, VA, U.S.A.). The cells were cultured in RPMI-1640 medium (GIBCO, NY, U.S.A.) supplemented with 10\% FBS (Shengma Yuanheng, Beijing China), $100 \mathrm{mg} / 1$ streptomycin, $100 \mathrm{IU} / \mathrm{ml}$ penicillin, and $0.03 \%$ L-glutamine and maintained at $37^{\circ} \mathrm{C}$ with $5 \% \mathrm{CO}_{2}$ in a humidified atmosphere.

Cytotoxity Assay L929 cells were incubated at $1 \times 10^{4}$ cells/well in 96-well plates (NUNC, Denmark). The cells were incubated with z-VAD-fmk, Ac-YVAD-cmk, z-DEVDfmk, z-IETD-fmk, DPQ, PD98059, SB203580, or SP600125 at given concentrations for $1 \mathrm{~h}$, and then treated with oridonin for different time periods. Cell growth was measured with a plate reader (TECAN SPECTRA, Wetzlar, Germany) by 3-(4,5-dimethylthiazol-2-yl)-2,5-diphenyltetrazolium (MTT) assay. The percentage of cell growth inhibition was calculated as follows:

cell death $(\%)=\left[A_{570}(\right.$ control $)-A_{570}($ oridonin $\left.)\right] / A_{570}($ control $) \times 100$

Observation of Morphological Changes L929 cells in RPMI-1640 containing 10\% FBS were seeded into 6-well culture plates and cultured for $12 \mathrm{~h}$. Control cultures were treated the vehicle $(0.05 \%$ DMSO). Oridonin $(41.2 \mu \mathrm{M})$ was added to the cell culture and the cellular morphology was observed using phase contrast microscopy at $12 \mathrm{~h}$ (Leica, Wetzlar, Germany).

Nuclear Damage Observed by Hoechst 33258 Staining Apoptotic nuclear morphology was assessed using a Hoechst 33258 as described previously. ${ }^{5}$ Cells were fixed with $3.7 \%$ paraformaldelyde for $30 \mathrm{~min}$ at room temperature, and then washed and stained with $167 \mu \mathrm{mol} / 1$ Hoechst 33258 at $37^{\circ} \mathrm{C}$ for $30 \mathrm{~min}$. The cells were washed and resuspended in PBS for morphological observation using a fluorescence microscoper (Leica).

LDH Activity-Based Cytotoxicity Assays LDH (lactate dehydrogenase) activity was assessed using a standardized kinetic determination (Zhongsheng LDH kit, Beijing, China). LDH activity was measured in both floating dead cells and viable adherent cells. Floating cells were collected from culture medium by centrifugation $(240 \times \boldsymbol{g})$ at $4{ }^{\circ} \mathrm{C}$ for $5 \mathrm{~min}$, and the LDH content from the pellets was used as an index of apoptotic cell death (LDHp). ${ }^{14)}$ The LDH released in the culture surpernatant (extracellular LDH, or LDHe) was used as an index of necrotic death, and the LDH present in the adherent viable cells as intracellular LDH (LDHi). The percentage of apoptotic and necrotic cell death was calculated as fol- lows:

apoptosis $\%=\mathrm{LDHp} /(\mathrm{LDHp}+\mathrm{LDHi}+\mathrm{LDHe}) \times 100$

necrosis $\%=\mathrm{LDHe} /(\mathrm{LDHp}+\mathrm{LDHi}+\mathrm{LDHe}) \times 100$

Western Blot Analysis L929 cells were treated with $41.2 \mu \mathrm{M}$ oridonin for $36 \mathrm{~h}$. Both adherent and floating cells were collected. Then Western blot analysis was performed as previously described, ${ }^{15)}$ with some modification. Briefly, the cell pellets were resuspended in lysis buffer consisting of Hepes $50 \mathrm{mmol} / 1 \mathrm{pH} 7.4$, Triton-X 100 1\%, sodium orthovanada $2 \mathrm{mmol} / \mathrm{l}$, sodium fluoride $100 \mathrm{mmol} / 1$, edetic acid $1 \mathrm{mmol} / \mathrm{l}$, PMSF $1 \mathrm{mmol} / 1$, aprotinin (Sigma, MO, U.S.A.) $10 \mathrm{mg} / \mathrm{l}$, and leupeptin (Sigma, MO, U.S.A.) $10 \mathrm{mg} / \mathrm{l}$, and lysed at $4{ }^{\circ} \mathrm{C}$ for $60 \mathrm{~min}$. After $13000 \times \boldsymbol{g}$ centrifugation for $15 \mathrm{~min}$, the protein content of the supernatant was determined by a protein assay reagent (Bio-Rad, U.S.A.). The protein lysates were separated by electrophoresis in $12 \%$ SDS polyacrylamide gel and blotted onto a nitrocellulose membrane. Proteins were detected using polyclonal antibody and visualized using anti-rabbit IgG conjugated with peroxidase (HRP) and 3,3-diaminobenzidine tetrahydrochloride (DAB) as the HRP substrate.

Statistical Analysis of the Data The data are expressed as means \pm S.D. Statistical comparisons were made by Student's $t$-test. $p<0.05$ was considered significant.

\section{RESULTS}

Cytotoxic Effects of Oridonin on L929 Cells Oridonin induced L929 cell death in a time- and concentration-dependent manner. Oridonin $8.6-68.7 \mu \mathrm{M}$ exerted potent inhibitory effects on L929 cell growth. Treatment of L929 cells with oridonin $68.7 \mu \mathrm{M}$ for $48 \mathrm{~h}$ induced approximately $91 \%$ cell death (Fig. 1).

Oridonin Induces L929 Cell Death by Affecting the Balance between Apoptosis and Necrosis To determine whether oridonin-induced L929 cell death was caused by apoptosis, we examined the morphological changes and DNA fragmentation. When L929 cells were cultured with $41.2 \mu \mathrm{M}$ oridonin for 6 , and $12 \mathrm{~h}$, marked morphological changes were observed as compared with the untreated control (Fig. 2). Oridonin-treated L929 cells underwent retraction of cellular processes and became round in shape at $3 \mathrm{~h}$ (Fig. 2B). By $12 \mathrm{~h}$, the majority of the L929 cells had be-

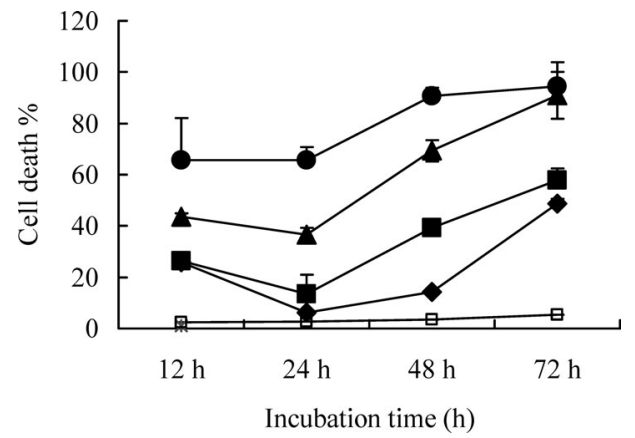

Fig. 1. Time Courses of Cell Death Induced by Oridonin

L929 cells were treated with oridonin at various doses for 12, 24, 36 and $48 \mathrm{~h}$. Cell viability was measured by MTT assay $(\square: 0.05 \%$ DMSO, $\bullet: 8.6, \mathbf{\square}: 17.2, \mathbf{\Lambda}: 34.3, \boldsymbol{\bullet}$ $68.7 \mu \mathrm{M}$ oridonin). $n=3, \bar{x} \pm$ S.D. 
A

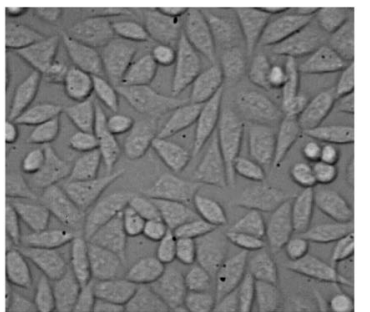

$\mathbf{E}$
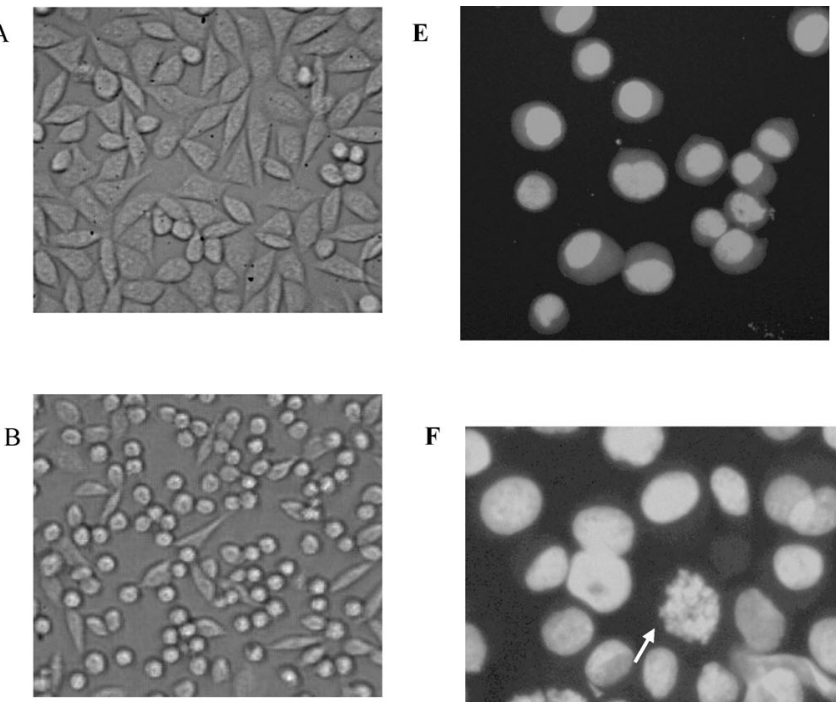

F

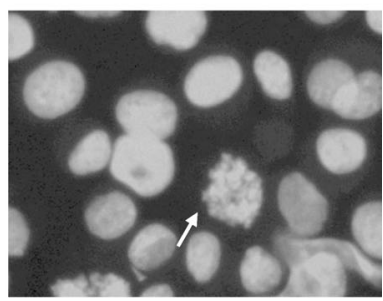

G

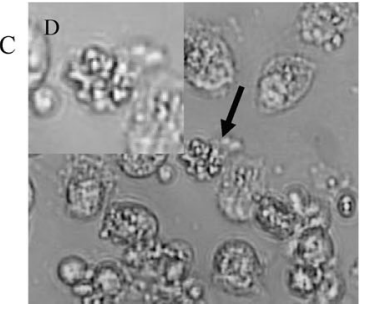

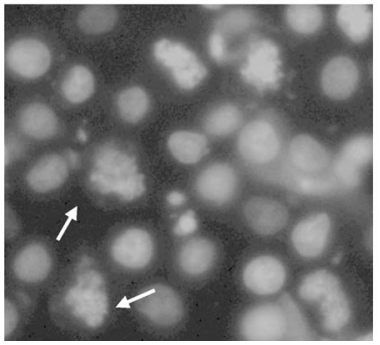

Fig. 2. Oridonin-Induced Morphological Changes in L929 Cells

The cells were incubated in 6-well culture plates. Changes in cellular morphology were examined at 6 (b), $12 \mathrm{~h}(\mathrm{c})(\times 100$ magnification), and $24 \mathrm{~h}(\mathrm{~d}, \mathrm{e})(\times 200$ magnification) in the absence (a) $(\times 100$ magnification) or presence of oridonin $41.2 \mu \mathrm{M}(\times 100$ magnification). L929 cells were incubated in medium alone (e) or medium containing $41.2 \mu \mathrm{m}$ oridonin (f), or $109.6 \mu \mathrm{m}$ oridonin (c) for $12 \mathrm{~h}$ and then the cells were stained with Hoechst 33258 and examined at $\times 100$ magnification.

come round, with shrunken nuclei (Fig. 2C). Some of these cells showed membrane blebbing and the nuclei were fragmented into apoptotic bodies (Fig. 2D). Untreated cells did not show these apoptotic characteristics (Fig. 2A). Morphological changes were further confirmed by Hoechst 33258 staining of cell nuclei (Figs. 2E, F). In the control group, nuclei of L929 cells were round and homogeneously stained, however, $41.2 \mu \mathrm{M}$ oridonin-treated cells showed marked blebbling of the nuclei and granular apoptotic bodies. At a high dose $(109.6 \mu \mathrm{M})$ of oridonin for $12 \mathrm{~h}$, necrotic nuclei with fluorescence emission were observed (Fig. 2G).

However, DNA ladders, another hallmark of typical apoptosis, were not observed in oridonin-treated L929 cells (data not shown). To further investigate whether oridonin initiated necrosis other than the apoptosis pathway, the rates of LDH release from viable cells, floating dead cells, and the culture medium were measured. In the presence of oridonin, although the number of apoptotic cells increased from $26.8 \%$ to $37 \%$; that of necrotic cells remained at $22.2 \%$ (Fig. 3). Therefore, oridonin induces L929 cell death by affcting the balance between apoptosis and necrosis.

Regulation of PARP in Caspase-Independent Cell Death Induced by Oridonin It is well known that caspases are required in apoptosis. We further examined the effects of caspase inhibitors on oridonin-induced L929 cell

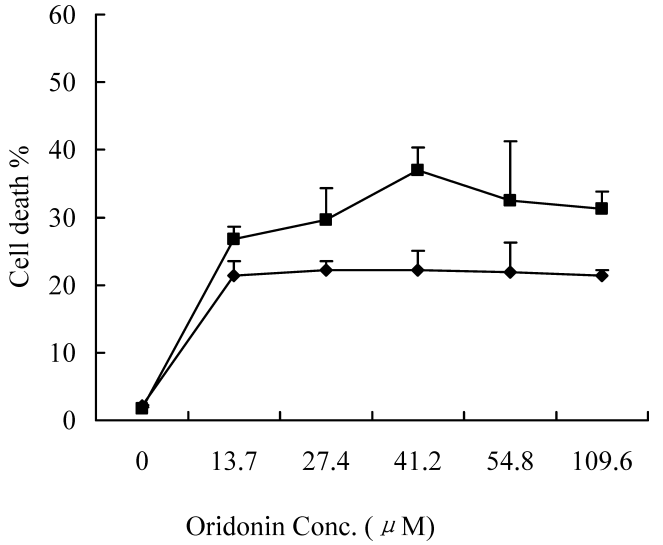

Fig. 3. Oridonin Induced L929 Cells LDH Release

Cells treated with various doses of oridonin (0.05\% DMSO (0), 13.7, 27.4, 41.2, $54.8,109.6 \mu \mathrm{M}$ ) for $12 \mathrm{~h}$ were measured by LDH activity-based assay. ( $\mathbf{\square}$ : apoptosis, necrosis). Data are mean \pm S.D. (bars) from 3 independent experiments.

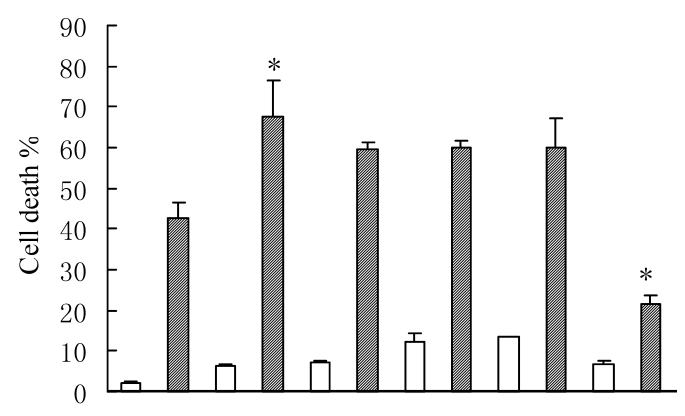

$$
\begin{aligned}
& 0.05 \% \text { DMSO } \\
& \text { Oridonin } \\
& \text { z-VAD-fmk } \\
& \text { z-DEVD-fmk } \\
& \text { z-IETD-fmk } \\
& \text { Ac-YVAD-cmk } \\
& \text { DPQ } \\
& \begin{array}{llllllllllll}
+ & + & + & + & + & + & + & + & + & + & + & + \\
- & + & - & + & - & + & - & + & - & + & - & + \\
- & - & + & + & - & - & - & - & - & - & - & - \\
- & - & - & - & + & + & - & - & - & - & - & - \\
- & - & - & - & - & - & + & + & - & - & - & - \\
- & - & - & - & - & - & - & - & + & + & - & - \\
- & - & - & - & - & - & - & - & - & - & + & +
\end{array}
\end{aligned}
$$

Fig. 4. Effect of Caspase Inhibitors on Oridonin-Induced L929 Cell Death

These cells were cultured in the presence or absence of caspase inhibitors, $z-V A D$ fmk $(20 \mu \mathrm{M}), \mathrm{z}$-DEVD-fmk $(20 \mu \mathrm{M})$, Ac-YVAD-cmk $(20 \mu \mathrm{M})$, z-IETD-fmk $(20 \mu \mathrm{M})$ or DPQ $(20 \mu \mathrm{M}), 60 \mathrm{~min}$ prior to the administration of oridonin $41.2 \mu \mathrm{M}$, and then incubated for 12 h. $n=3, \bar{x} \pm$ S.D. $* p<0.05 v s$. treatment with oridonin $41.2 \mu \mathrm{M}$.

death. Unexpectedly, a pan-caspase inhibitor, z-VAD-fmk, rendered the cells even more sensitive to oridonin and an inhibitor of caspase-3, z-DEVD-fmk, also effectively augmented the cell death (Fig. 4). Caspase-1 and caspase-8 had the same effect on L929 cell death. At $12 \mathrm{~h}$, z-VAD-fmk increased the cell death rate from $42.8 \%$ (cultured with oridonin alone) to $67.8 \%$. It was reported that some necrotic cases were thought to be caspase-independent and PARP-mediated. ${ }^{8)}$ Thus, we examined the possibility that PARP participated in oridonin-induced L929 cell death. As shown Fig. 4, $20 \mu \mathrm{M}$ DPQ reduced cell death from $42.8 \%$ to $21.4 \%$. Moreover, with 24 to $36 \mathrm{~h}$ incubation with oridonin, expression of PARP was down-regulated (Fig. 5). Importantly, the assumption that caspase-3 is not responsible for PARP cleavage in L929 cells gained further support from the observation that application of the pan-caspase inhibitor z-VAD-fmk in 


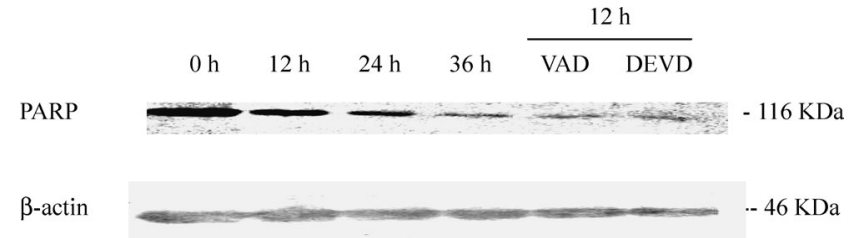

Fig. 5. Expression of PARP in Oridonin-Treated L929 Cells

The cells were treated with $41.2 \mu \mathrm{M}$ oridonin for $0,12,24$, and $36 \mathrm{~h}$. Cell lysates were separated by $12 \%$ SDS-PAGE electrophoresis, and PARP protein bands were detected by Western blot analysis. $\beta$-Actin was used as an equal loading control.

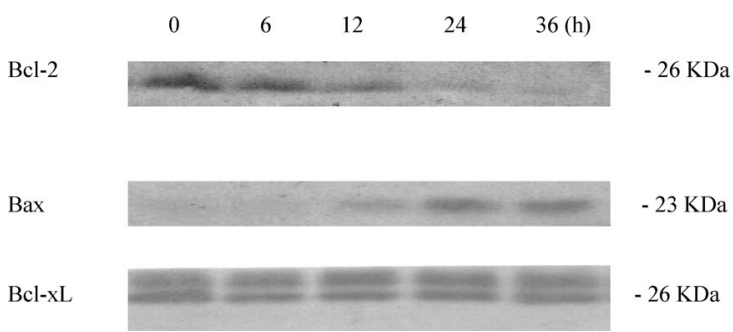

Fig. 6. Expression of Bcl-2, Bax and Bcl-xL in Oridonin-Treated L929 Cells

The cells were treated with $41.2 \mu \mathrm{M}$ oridonin for $0,6,12,24$ and $36 \mathrm{~h}$. Cell lysates were separated by $12 \%$ SDS-PAGE electrophoresis, and the protein bands were detected by Western blot analysis.

combination with oridonin did not inhibit PARP cleavage. On the contrary, z-VAD-fmk and z-DEVD-fmk increased the PARP degradation at $12 \mathrm{~h}$. These results suggested that oridonin-induced L929 cell death required PARP degradation in a caspase-independent manner.

Involvement of Bcl-2 Family Proteins in Oridonin-Induced Cell Death The products of Bcl-2-related proteins are known to play a role in either inhibition or promotion of apoptotic cell death. ${ }^{16)}$ To determine whether Bcl-2 family proteins are involved in oridonin-induced L929 cell death, we examined the effects of oridonin on the expression of the Bcl-2 family members by Western blot analysis. The results showed that treatment of L929 cells with $41.2 \mu \mathrm{M}$ oridonin caused a down-regulation of Bcl-2 protein. In contrast, Bax was upregulated by oridonin. The expression level of Bcl-xL was not affected by oridonin treatment (Fig. 6).

Modulation of MAPK Molecules by Oridonin MAPK signaling pathways have been shown to play important roles in cell growth and death. ${ }^{11)}$ To determine whether the regulation of the MAPK cascade is involved in oridonin-induced cell death, specific inhibitors for p38 (SB203580), JNK (SP600125), and MEK/ERK (PD98059) were applied to assess the function of MAPKs in oridonin-induced L929 cell death. After $12 \mathrm{~h}$ incubation with oridonin, $10 \mu \mathrm{M}$ PD98059 decreased oridonin-induced cell death from 56.8 to $28.5 \%$. However, SB203580 and SP600125 only slightly blocked cell death (Fig. 7). To further confirm this, MAPK family protein expression was examined by Western blot analysis. As shown in Fig. 8, the expression levels of p38, ERK, and JNK proteins were not affected by oridonin. However, administration of oridonin significantly and persistently increased the phosphorylated ERK, weakly down-regulated phospho-p38, but did not affect the phosphorylation status of JNK.

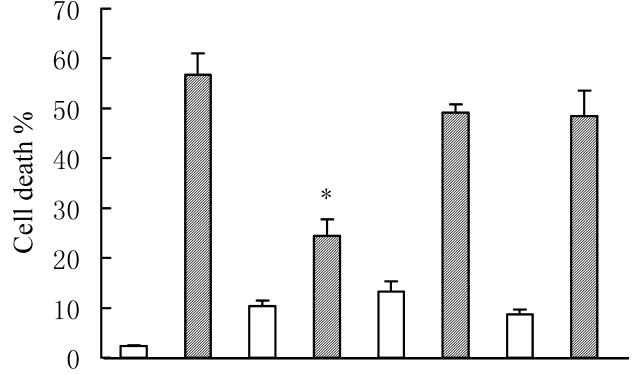

$\begin{array}{lcccccccc}0.05 \% \text { DMSO } & + & + & + & + & + & + & + & + \\ \text { Oridonin } & - & + & - & + & - & + & - & + \\ \text { PD98059 } & - & - & + & + & - & - & - & - \\ \text { SB203580 } & - & - & - & - & + & + & - & - \\ \text { SP600125 } & - & - & - & - & - & - & + & +\end{array}$

Fig. 7. Effect of MAPK Inhibitors on Oridonin-Induced L929 Cell Death

These cells were cultured in the presence or absence of the MAPK inhibitors PD98059 $(10 \mu \mathrm{M}), \operatorname{SB} 203580(10 \mu \mathrm{M})$, and SP600125 $(10 \mu \mathrm{M}) 60$ min prior to the administration of oridonin $41.2 \mu \mathrm{M}$, and then incubated for $12 \mathrm{~h} . n=3, \bar{x} \pm$ S.D. $* p<0.05$ $v s$. treatment with oridonin $41.2 \mu \mathrm{M}$.
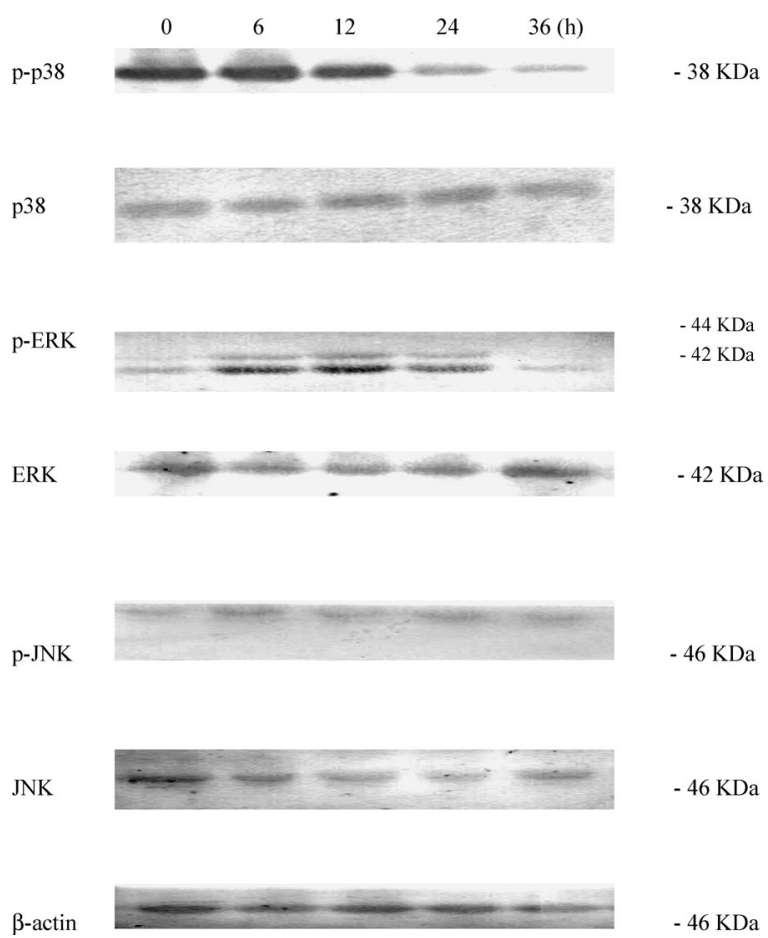

Fig. 8. Oridonin-Induced Up-Regulated ERK Phosphorylation, DownRegulated p38 Phosphorylation and Did Not Affect JNK Expression

The cells $\left(3.0 \times 10^{6}\right)$ were treated with oridonin. After $36 \mathrm{~h}$, the cell lysates were separated by $12 \%$ SDS-PAGE, and the phospho-ERK, phospho-p38, phospho-JNK and total ERK, p38, and JNK proteins bands were detected by Western blot analysis. Experiments repeated 3 times gave similar results.

\section{DISCUSSION}

It is well known that the majority of death signals pass through two distinct pathways: apoptosis and necrosis. Fasmediated cell death occurs not only by apoptosis but also by necrosis, depending on the cellular context. Fas-induced necrosis requires the adaptor protein FADD and the Fas-interacting serine/threonine kinase receptor-interacting protein 
(RIP), whereas caspase- 8 seems to be dispensable. ${ }^{17)}$ Some signaling pathways, such as death receptors, MAPK kinase cascades, and mitochondria, participate in both processes, and through regulating these pathways it is possible to switch from apoptosis to necrosis.

In this study, we demonstrated that oridonin inhibited the proliferation on L929 cells in vitro in a dose- and time-dependent manner. There was significant growth inhibition at the doses of oridonin ranging from 8.6 to $68.7 \mu \mathrm{M}(p<0.05)$, compared with the medium control group. Based on changes of cellular morphology, DNA fragmentation and LDH assay, we concluded that oridonin induces L929 cell death via its effect on the balance between apoptosis and necosis.

Previous reports have demonstrated that caspase inhibitors stimulated TNF $\alpha$-induced L929 necrosis. This sensitization may be correlated with the production of reactive oxygen radicals. ${ }^{18)}$ Surprisingly, some workers found that the pancaspase inhibitor z-VAD-fmk prevents CD95-mediated apoptosis and potentiates TNF-induced necrosis. Meanwhile, TNF $\alpha$ but not CD95 induced the PARP degradation and PARP inhibitor 3-aminobenzamide (3AB) could significantly protect against TNF-mediated death, and the protection against TNF-induced death by PARP inhibition largely correlated with preservation of the cellular ATP pool, whereas TNF sensitization by the caspase inhibitor was associated with a dramatic ATP loss. ${ }^{8,19-21)}$ In addition, during apoptosis, PARP, a DNA-associating nuclear protein, is activated by cleavage of the $116-\mathrm{KD}$ proenzyme to an $85-\mathrm{KD}$ cleavage product. $^{22)}$ In this study, although marked apoptotic bodies appeared at $12 \mathrm{~h}$, DNA fragmentation induced by oridonin was not observed. Pan-caspase inhibitor and caspase-3, -8, and -1 inhibitors did not block cell death, but augmented the oridonin-induced L929 cell death. However, a PARP inhibitor, DPQ, suppressed L929 cell death induced by oridonin, and the intensity of the uncleaved 116-KD band appeared to decrease after $12 \mathrm{~h}$ of treatment with oridonin. Moreover, the $85-\mathrm{KD}$ band indicative of cleavage by caspase3 could not be detected. Pan-caspase and caspase- 3 inhibitors failed to suppress PARP degradation, but augmented it. These observations suggested that some protease(s) different from caspase- 3 is responsible for the degradation of PARP in L929 cells, and protection against oridonin-induced death by PARP inhibition might be linked with the conservation of cellular ATP, as some workers have previously reported. ${ }^{19,21)}$ These results suggested that PARP cleavage was required in oridonin-induced L929 cell death, however, caspases exerted protective effects in this process.

The MAPK family, which includes ERK, JNK and p38 MAPK, is reported to play important roles in apoptosis and necrosis. ${ }^{23)}$ Activation of the distinct MAPK subtype cascade is dependent on the types of cells and the stimuli, and the functional role of each MAPK subtype may be different according to the cell types. Several previous reports have demonstrated that p38 MARP might function as death signals when cells are treated with diverse cellular stress. ${ }^{23,24)}$ However, it has been reported recently that the activation of p38 prevent L929 cell death. ${ }^{25)}$ The results of the present study show that treatment of L929 cells with oridonin caused marked activation of ERK and inactivation of p38 MARP, and did not affect phospho-JNK expression. These results indicated that p38 inactivation and ERK activation might promote oridonin-induced cell death. The JNK signaling pathway is not involved in this process. In addition, L929 cells treated with oridonin exhibited elevated levels of proapoptotic Bax expression, while anti-apoptotic Bcl-2 was down-regulated, and did not affect other anti-apoptotic protein Bcl-xL expression. This observation suggests that the balance between Bcl-2 and Bax expression is essential for oridonin-induced cell death.

In summary, we have demonstrated that oridonin triggered atypical intracellular regulation to induce L929 cell death. The mechanism is in part due to modulation of ERK and p38 MARP, accompanied by the down-regulation of Bcl-2 and up-regulation of Bax. Moreover, PARP degradation participated in this process in a caspase-independent manner.

\section{REFRENCES}

1) Zhang C. L., Wu L. J., Tashiro S., Onodera S., Ikejima T., Chin. Pharmacol. Bull., 19, 525-529 (2003).

2) Osawa K., Yasuda H., Maruyama T., Morita H., Takeya K., Itokawa H., Chem. Pharm. Bull., 42, 922 -925 (1994).

3) Fuji K., Node M., Sai M., Fujita E., Takeda S., Unemi N., Chem. Pharm. Bull., 37, 1472-1476 (1989).

4) Li X. T., Lin C., Li P. Y., Acta Pharmacol. Sin., 7, $361-363$ (1986).

5) Zhang C. L., Wu L. J., Tashiro S., Onodera S., Ikejima T., J. Asia Natl. Prod. Res., 6, 127-138 (2004).

6) Nicholson D. W., Ali A., Thornberry N. A., Vaillancourt J. P., Ding C. K., Gallant M., Gareau Y., Griffin P. R., Labelle M., Lazebnik Y. A., Nature (London), 376, 37-43 (1995).

7) Vercammen D., Beyaet R., Denecker G., Goossens V., Van Loo G., Declercq W., Grooten J., Fiers W., Vandenabeele P., J. Exp. Med., 187, 1477-1485 (1998).

8) Los M., Mozoluk M., Ferrari D., Stepczynska A., Stroh C., Renz A., Herceg Z., Wang Z. Q., Schulze-Osthoff K., Mol. Biol. Cell., 13, 978-988 (2002).

9) Kroemer G., Nat. Med., 3, 614 -619 (1997).

10) Klekotka P. A., Santoro S. A., Wang H., Zutter M. M., J. Biol. Chem., 276, 32353-32361 (2001).

11) Schaeffer H. J., Weber M. J., Mol. Cell. Biol., 19, 2435-2444 (1999).

12) Zhang Y., Wu L. J., Tashiro S., Onodera S., Ikejima T., Biol. Pharm. Bull., 26, 1543-1547 (2003).

13) Kubo I., Kamikawa T., Kubota T., Tetrahedron, 30, 615-618 (1974).

14) Kim Y. M., Talanian R. V., Billiar T. R., J. Biol. Chem., 272, 31138 31148 (1997).

15) Suzuki K., Hino M., Kutsuna H., Hato F., Sakamoto C., Takahashi T., J. Immunol., 167, 5940-5947 (2001).

16) Adams J. M., Cory S., Science, 281, 1322-1326 (1998).

17) Vercammen D., Beyaert R., Denecker G., Goossens V., Van Loo G., Declercq W., J. Exp. Med., 187, 1477-1485 (1998).

18) Goossens V., Stange G., Moens K., Pipeleers D., Grooten J., Antioxid. Redox Signal, 1, 285-295 (1999).

19) Strelow B. A., Bernardo K., Adam-Klages S., Linke T., Sandhoff K., Kronke M., J. Exp. Med., 192, 601-611 (2000).

20) Tafani M., Schneider T. G., Pastorino J. G., Farber J. L., Am. J. Pathol., 156, $2111-2121$ (2000).

21) Schulze-Osthoff K., Krammer P. H., Droge W., EMBO J., 13, 45874596 (1994).

22) Lazebnik Y. A., Kaufmann S. H., Desnoyers S., Poirier G. G., Earnshaw W. C., Nature (London), 371, 346-347 (1994).

23) Xia Z., Dikens M., Raingeaud J., Davis R. J., Greenberg M. E., Science, 270, 1326-1331 (1995).

24) Minden A., Karin M., Biochim. Biophys. Acta, 1333, f85-f104 (1997).

25) Morita Y., Naka T., Kawazoe Y., Fujimoto M., Narazaki M., Nakagawa R., Fukuyama H., Nagata S., Kishimoto T., Proc. Natl. Acad. Sci. U.S.A., 97, 5405-5410 (2000). 